\title{
A MINI REVIEW ON PREPARATION, CHARACTERIZATION, AND APPLICATIONS OF SILVER IODIDE NANOPARTICLES
}

\begin{abstract}
GEORGE PP*
Department of Basic Science and Humanities, Mangalam College of Engineering, (affiliated to APJ Abdul Kalam Technological University, CET campus, Thiruvananthapuram and approved by AICTE, New Delhi), Kottayam, Kerala, India. Email: georgepanikulangara@yahoo.in
\end{abstract}

Received: 04 September 2021, Revised and Accepted: 18 December 2021

\section{ABSTRACT}

The synthesis of silver iodide nanoparticles for variety of applications such as photocatalyst and antibacterial properties has attracted broad interest due to the extraordinary properties of these materials. The preparation of silver iodide nanoparticles through a physical or chemical reduction process is the most common methodology applied to obtain nanoparticles with the required size, shape, and surface morphology. This review paper discusses the details concerning the past and recent advancement of the synthesis and characterization of silver iodide nanoparticles and also composite silver iodide/carbon nanotubes nanoparticles. A review on the advantages of various techniques, which aim to achieve the photo catalyst and antibacterial properties is also included. A brief summary concerning the recent challenges and improvement approaches is presented at the end of this review.

Keywords: AgI, AgI/carbon nanotubes, Characterization, Antibacterial property, Photo catalysis, Applications.

(c) 2022 The Authors. Published by Innovare Academic Sciences Pvt Ltd. This is an open access article under the CC BY license (http://creativecommons.org/ licenses/by/4.0/) DOI: http://dx.doi.org/10.22159/ajpcr.2022v15i2.43054. Journal homepage: https://innovareacademics.in/journals/index.php/ajpcr

\section{INTRODUCTION}

Silver halides ( $\mathrm{AgX}, \mathrm{X}=\mathrm{Cl}, \mathrm{Br}$, I) hybrids [1-3] were widely attracted broad attention because of their excellent photocatalytic performance. AgI, which has been well known as a photosensitive material and extensively used in photography yields, is one of the members of silver halide materials. At present, its excellent photocatalytic performance has also attracted intense investigation [4,5]. The synthesis of nanomaterials with various crystal sizes, shapes, and morphology is an outstanding aspect from the practical point of view [6-9]. In addition, AgI has been investigated extensively because of their enhancing applications in the fields of solid state ionics and photography. Further, nano-sized AgI is used as new functional material in a variety of fields such as magnetic, medicine, photography, antibacterial, electronic, catalytic, and optical fields [10-11]. The synthesis methods for the preparation of silver iodide nanomaterials include template method [12], electrospinning method [13], ultrasonic spray pyrolysis [14], and sonochemical methods [15].

Green nanotechnology for the synthesis of metal nanoparticles is an emerging area of research in the fields of nanotechnology with a lot of applications including optical, luminescence, and photo-catalytic properties [16-19]. The use of plant extracts, eco-friendly aqueous medium, and mild reaction conditions makes the method advantageous over other chemical methods. In the last decade, different synthetic approaches involving plant extract medium had made a big impact due to its low cost, energy efficient, and non-toxic solvent medium [20].

AgI nanoparticles fabricated from the above methods including green synthesis have been examined for their photocatalytic activity, homogenous catalyst, and antibacterial applications. The preparation method and applications of fabricated AgI nanoparticles are summarized in Figs 1 and 2. With the outstanding advantages of photocatalyst, antibacterial properties and optical enhancing properties, silver iodide nanoparticles can be directly used as films, coatings, catalytic materials, and water treatment.

The embedding of AgI with other semiconductors was also investigated [21-27]. $\mathrm{Xu}$ et al. [21] took the g- $\mathrm{C}_{3} \mathrm{~N}_{4}$ as the supporting material and synthesized $\mathrm{AgX} / \mathrm{g}-\mathrm{C}_{3} \mathrm{~N}_{4}$ hybrid materials $(\mathrm{X}=\mathrm{Br}, \mathrm{I})$. In their studies, the AgX not only maintained well its structures on the surface of $\mathrm{g}-\mathrm{C}_{3} \mathrm{~N}_{4}$ but also displayed enhanced photocatalytic activity due to the formation of heterojunction structure. The strategy of coupling AgI with semiconductor has improved the properties of AgI. Similarly, it is hoped that the combination of carbon nanotubes (CNT) and AgI can improve the performance of the hybrid. Eliseev et al. [28] prepared $\mathrm{AgCl}$ intercalated in CNT. The results showed that the hybrids have higher photocatalytic degradation efficiency.

In this review, we have discussed the variety of synthetic approaches of AgI nanoparticles and their characterization using X-ray Diffraction (XRD), Scanning Electron Microscopy (SEM), High Resolution Transmission Electron Microscopy (HRTEM), ultraviolet (UV)-visible, and Fourier transform infrared (FTIR) spectroscopy. In addition, their application in catalysis, biological sciences, and other disciplines have been assessed.

Huaming et al. had reported that the CNT/AgI hybrids with variety of CNT content were fabricated through a facile solvothermal method [29]. The synthesis of CNT/AgI composite takes place in three steps: Preparation of CNT dispersion in ethylene glycol by ultrasonic treatment solution is the first step. In the second step, silver nitrate $\left(\mathrm{AgNO}_{3}\right)$ was added into a $50 \mathrm{~mL}$ beaker. In the last step, a $4 \mathrm{~mL}$ of above CNT dispersion solution (CNT: $\mathrm{AgNO}_{3}$ in mass ratio of $0.1 \%$ ) was added to the $\mathrm{AgNO}_{3}$ beaker, and then stirring for $0.5 \mathrm{~h}$. Subsequently, potassium iodide (KI) was added to above solution and kept stirring for another $30 \mathrm{~min}$ at room temperature. Finally, the reaction mixture was transferred to $25 \mathrm{~mL}$ Teflon-lined stainless-steel autoclaves and kept for $20 \mathrm{~h}$ at $140^{\circ} \mathrm{C}$. The final samples were labeled as $0.1 \% \mathrm{CNT} / \mathrm{AgI}$. $0.3 \% \mathrm{CNT} / \mathrm{AgI}$ and was fabricated using $12 \mathrm{~mL}$ CNT dispersion solution and similarly 1\% CNT/AgI was fabricated using $40 \mathrm{~mL}$ CNT dispersion solution. Synthesis of $\mathrm{Ag} / \mathrm{AgI}$ was achieved without adding the CNT dispersion solution. Huaming and Hui have studied the photocatalytic activities of the as-fabricated samples toward photo-degradation of $\mathrm{RhB}$ in water. Fig. 3 shows the photocatalytic reaction results of asfabricated Ag/AgI and CNT/AgI composites with different CNT contents. It shows that RhB self-decomposition was negligible under visible light irradiation. When the photocatalyst was added, the concentration of the $\mathrm{RhB}$ gradually decreased under the visible light. The dye started degrading after $24 \mathrm{~min}$ and the degradation efficiency of $\mathrm{RhB}$ over 
Ag/AgI, 0.1\% CNT/AgI, 0.3\% CNT/AgI, and 1\% CNT/AgI were 56.17\%, $84.43 \%, 88.1 \%$, and $67.81 \%$, respectively. After irradiation for $48 \mathrm{~min}$, the degradation efficiency of RhB over Ag/AgI, 0.1\% CNT/AgI, 0.3\% CNT/AgI, and 1\% CNT/AgI was 88.91\%, 97.71\%, 98.07\%, and 93.27\%, respectively. It is clear that the photoactivity of $\mathrm{Ag} / \mathrm{AgI}$ was greatly enhanced after the introduction of CNT. The $0.3 \%$ CNT/AgI displayed the highest photocatalytic activity, which has a 31\% improvement compared to pure $\mathrm{Ag} / \mathrm{AgI}$ materials after 24 min irradiation. When the CNT content was higher than $0.3 \%$, a further increase of CNT content caused a decrease of the photocatalytic activity. It can also be seen that the photoactivity of the $0.1 \% \mathrm{CNT} / \mathrm{AgI}$ and $0.3 \% \mathrm{CNT} / \mathrm{AgI}$ is very close,

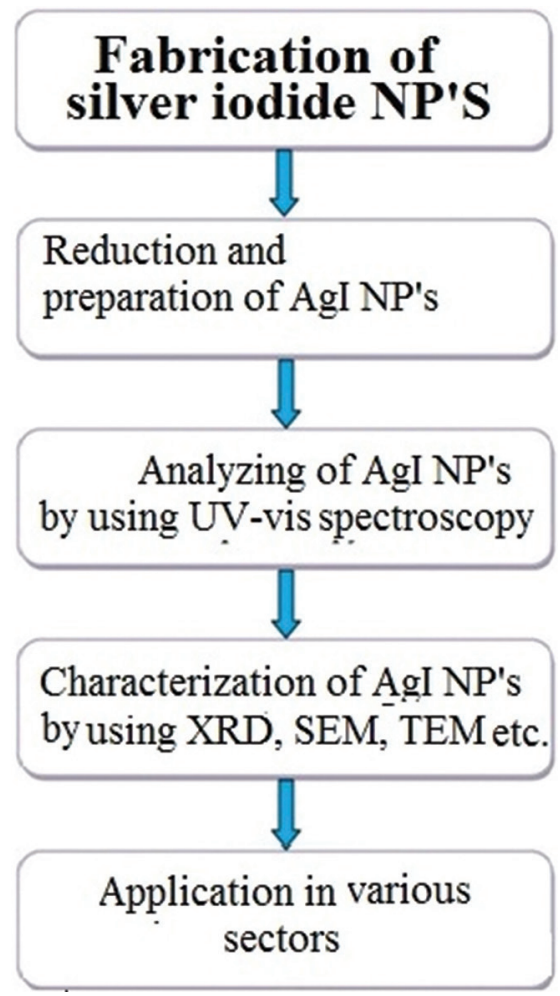

Fig. 1: Synthesis of AgI nanoparticles

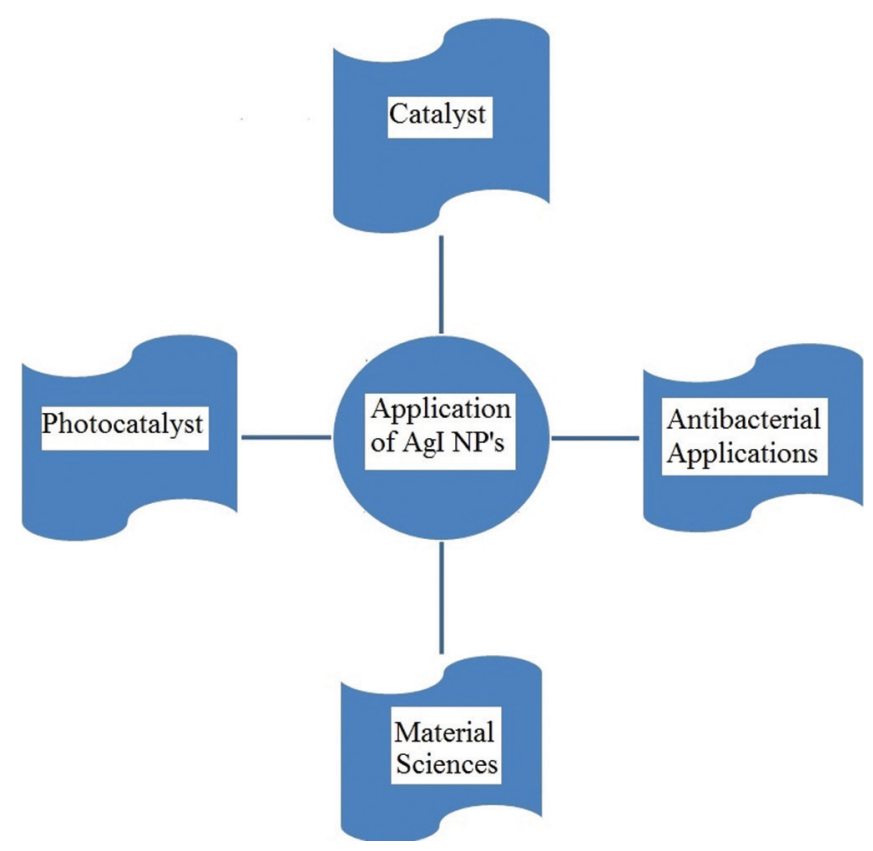

Fig. 2: Application of AgI nanoparticles which may be due to the parallel crystal structure. The modification of a little CNT to Ag/AgI has changed the crystal phase of AgI and led to forming smaller size particles as well as being advantage to charge transfer, which ultimately enhanced the photoactivity of the hybrid.

Fig. 4 demonstrates the PL spectra of Ag/AgI and CNT/AgI composites. The PL intensity of the as-fabricated samples gradually decreased with the increase of the introduced CNT content, which means more efficient charge transfer, higher migration, and lower recombination in the CNT/AgI composites compare to the pure Ag/AgI. PL analysis inferred that introducing CNT is an effective way to improve the electron-hole separation efficiency and decrease the recombination. The results reveal the reason why the CNT/AgI showed improved photoactivity.

Hawari et al. have reported the synthesis of AgI nanoparticles from the reagents $\mathrm{AgNO}_{3}$ and $\mathrm{KI}$ using distilled water as solvent [30]. The reaction completed within $15 \mathrm{~min}$, and then filtered and left to dry for a day. The precipitates were collected, repeatedly washed with distilled water and then sintered at $250^{\circ} \mathrm{C}$ for $5 \mathrm{~h}$

Fabrication of AgI nanoparticles is achieved using $\mathrm{AgNO}_{3}$ and $\mathrm{KI}$ under ultrasound power in the presence of sodium dodecyl sulfate as surfactant [31]. The yellow precipitate was separated by centrifugation and washed with distillated water and ethanol to remove impurities for several times and then dried. AgI nanoparticles have been characterized by SEM, Transmission Electron Microscopy (TEM), XRD, UV-visible, and

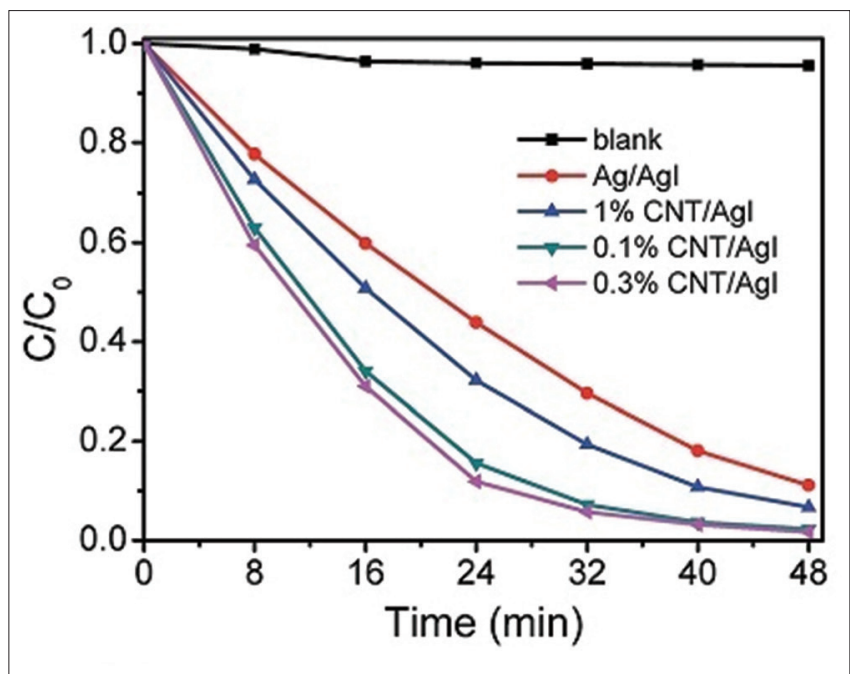

Fig. 3: Photocatalytic degradation of RhB under visible light irradiation

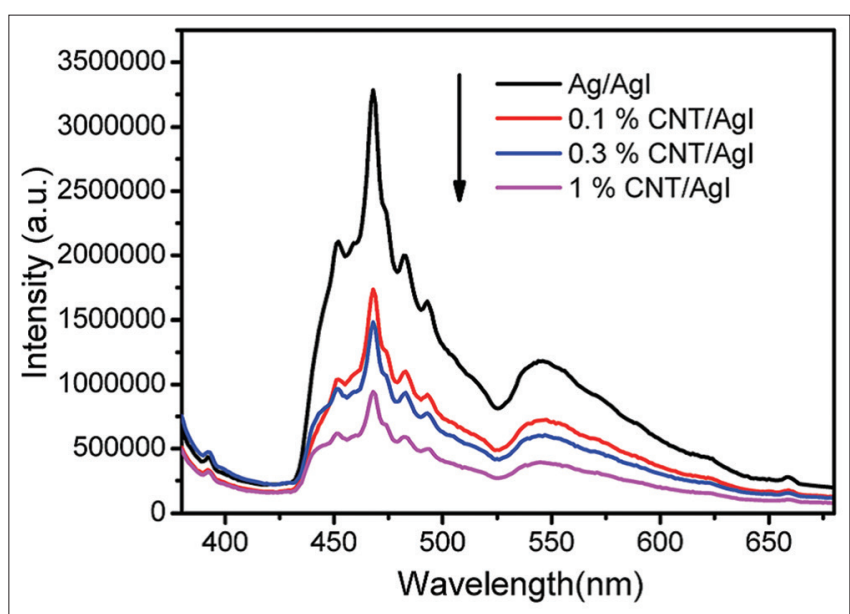

Fig. 4: PL spectra of Ag/AgI and carbon nanotubes/AgI composites 
FTIR spectroscopy and their application as catalyst for the synthesis of benzofurans has been accessed. SEM image of AgI nanoparticles prepared using surfactant was presented in Fig. 5. This result shows that spherical AgI nanoparticles were obtained from $\mathrm{AgNO}_{3}$ and $\mathrm{KI}$ with particle size $45-50 \mathrm{~nm}$.

The influence of various catalysts on the synthesis of benzofuran 4 is summarized in Table 1 . As shown, we found that silver iodide is the most effective catalyst for this organic reaction. Moreover, AgI NPs afforded excellent yields in shorter reaction times in comparison with bulk AgI. The increased catalytic activity of AgI NPs over the commercially available bulk AgI may be attributed to the higher surface area of nanomaterials. This is thought to be due to AgI NPs morphology which has been shown in the SEM image.

The AgI nanoparticles have unique optical, electrical, and catalytic properties that make it useful in industrial applications. Li et al. have reported the fabrication of AgI nanoparticles by using a spinning disk reactor (SDR) method at ambient temperature in a continuous mode of operation. The reaction was carried out in a SDR by injecting two streams of $\mathrm{AgNO}_{3}$ and $\mathrm{KI}$ solution continuously. The reaction time was less than $1 \mathrm{~min}$, which was considerably shorter than the conventional wet chemical process [32].

Yamasaki et al. have demonstrated the fabrication of AgI nanoparticles by treating $\mathrm{AgNO}_{3}$ with $\mathrm{KI}$ in an aqueous solution in the presence of poly-N-vinyl-2-pyrrolidone as a protective polymer. They have been characterized by the XRD, TEM and differential scanning calorimetry (DSC). TEM measurements indicates that the AgI NPs have a mean diameter size of $6.3 \mathrm{~nm}$ [33].

Hexagon-shaped $\beta$-AgI nanoplates were synthesized via a simple solvothermal route in reactable ionic liquids [34]. Feng et al. demonstrated the application of $\beta$-AgI nanoplates as photocatalyst for the degradation of $\mathrm{RhB}$ dye under the visible light irradiation. In a typical preparation, the mixture $\left(\mathrm{AgNO}_{3}\right.$ and $[\mathrm{Bmim}]$ I solution) was transferred into Teflon-line autoclave and heated at different temperatures for $24 \mathrm{~h}$ and then cooled to the room temperature. The product was centrifuged, washed with water and ethanol for several times, and dried for $8 \mathrm{~h}$. The photocatalysts samples heated at $100^{\circ} \mathrm{C}$,

Table 1: One-pot synthesis of benzofuran 4 by various catalysts including AgI nanoparticles

\begin{tabular}{llll}
\hline Entry & Catalyst & Time (h) & Yields (\%) \\
\hline 1 & CuI & 3.5 & 65 \\
2 & $\mathrm{CuCl}$ & 5 & 55 \\
3 & $\mathrm{AgBr}$ & 4.5 & 52 \\
4 & $\mathrm{AgI}$ & 3 & 60 \\
5 & $\mathrm{CuI}$ & 2 & 86 \\
6 & $\mathrm{AgI}$ & 1 & 93 \\
\hline
\end{tabular}

$120^{\circ} \mathrm{C}, 140^{\circ} \mathrm{C}, 160^{\circ} \mathrm{C}, 180^{\circ} \mathrm{C}$, and $200^{\circ} \mathrm{C}$ for $24 \mathrm{~h}$ were, respectively, named T100, T120, T140, T160, T180, and T200. The photocatalysts were characterized by XRD, SEM, X-ray photoelectron spectroscopy, diffuse reflectance spectra, and thermo gravimetric and DSC (DSC). The hexagon $\beta$-shaped AgI nanoplates exhibited high visible light photocatalytic activity for the degradation of RhB. The high stable of $\beta$-AgI was due to the presence of the (Bmim)+ on the surface of the sample. RhB dye was chosen as the model pollutant to investigate the photocatalytic activity and stability of the sample under the visible light irradiation. Fig. 6 demonstrates the photocatalytic activity of the samples for the degradation of RhB dye. For T140, T160, T180, and T200 photocatalysts, the corresponding degradation efficiency is $96.6 \%$, $89.4 \%, 38.5 \%$, and $29.6 \%$, respectively. Under the same condition, the photocatalytic activity of the T100, T120, and T140 sample had the similar degradation efficiency. The photocatalytic activity was in the following order: $\mathrm{T} 100 \approx \mathrm{T} 120 \approx \mathrm{T} 140>\mathrm{T} 160>\mathrm{T} 180>\mathrm{T} 200$.

Photocatalytic mechanism of $\beta$-AgI material: Photocatalytic oxidation reaction of organic pollutants explained in four stages: (1) Photon absorption by semiconductor; (2) photo-generated electrons and holes; (3) the separation of photo-generated electrons and holes; and (4) transition of electrons and holes to the surface and reactions with pollutants. The radicals and holes trapping experiments could detect the main oxidative species in the photocatalytic process for revealing the photocatalytic mechanism of $\beta$-AgI sample. Visible light irradiation results the photogenerated electron-hole pairs were formed. e- reacted with $\mathrm{O}_{2}$ to form $\bullet \mathrm{O}_{2}$ - Then hydroxyl radicals could be obtained. The generated $\bullet \mathrm{OH}^{2}$ radicals reacted with organic pollutant, for degradation. The photocatalytic degradation mechanism of organic pollutants by $\beta$-AgI is shown in Fig. 7 .

The measured band gap energy of the AgI sample is about $2.8 \mathrm{eV}$ (Fig. 8). The band gap was close to the value reported in the previous literature [35]. From this result, it could be inferred that the AgI samples might have good photocatalytic activity under visible light irradiation.

Kaliammal et al. demonstrated the chemical synthesis of AgI nanoparticles. An aqueous solution of iodine was mixed with polymer (PEG-PPG-PEG) protected silver nanoparticles for 30 min under magnetic agitation resulted the pale yellow colored solution and confirmed the formation of silver iodide nanoparticles [36]. The particle size of the nanoparticles has been determined by XRD and HRTEM. The optical characterization was carried out using UV-visible absorption and photoluminescence spectroscopy. The catalytic property of silver iodide nanoparticles was investigated using methyl orange. Antibacterial activity was determined using cup diffusion method for a Gram-positive and Gram-negative organism such as Escherichia coli ATCC 8739 (Gram negative) and Staphylococcus aureus ATCC 6538 (Gram positive). Fig. 9 shows the HRTEM images of silver iodide nanoparticles. Fig. 9a showed that the silver iodide nanoparticles were small in size in the range of $10-15 \mathrm{~nm}$ and spherical in shape. This value agrees well with the particle size obtained by the XRD analysis $(9 \mathrm{~nm})$. Fig. $9 \mathrm{~b}$ shows the

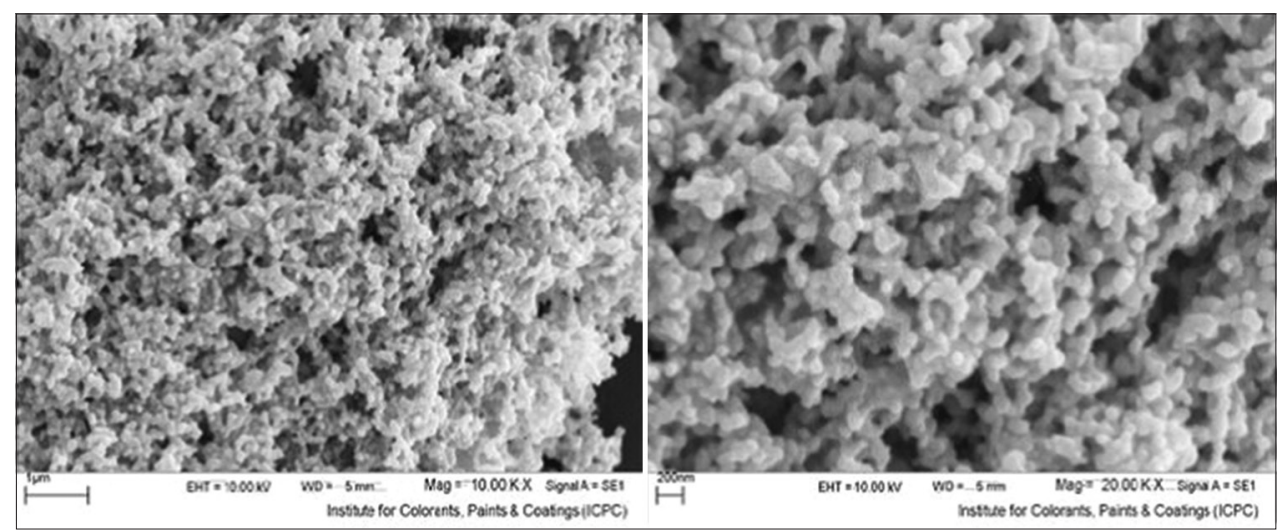

Fig. 5: The scanning electron microscopy image of AgI nanoparticles 
selected area electron diffraction pattern of silver iodide nanoparticles, which shows partial crystalline nature in this case (AgI-AB-1)

Fig. 10 shows the UV visible spectrum for silver iodide nanoparticles shows an excitonic peak at $432 \mathrm{~nm}$. This value agrees well with the value reported by Chen et al. for silver iodide nanoparticles [37]

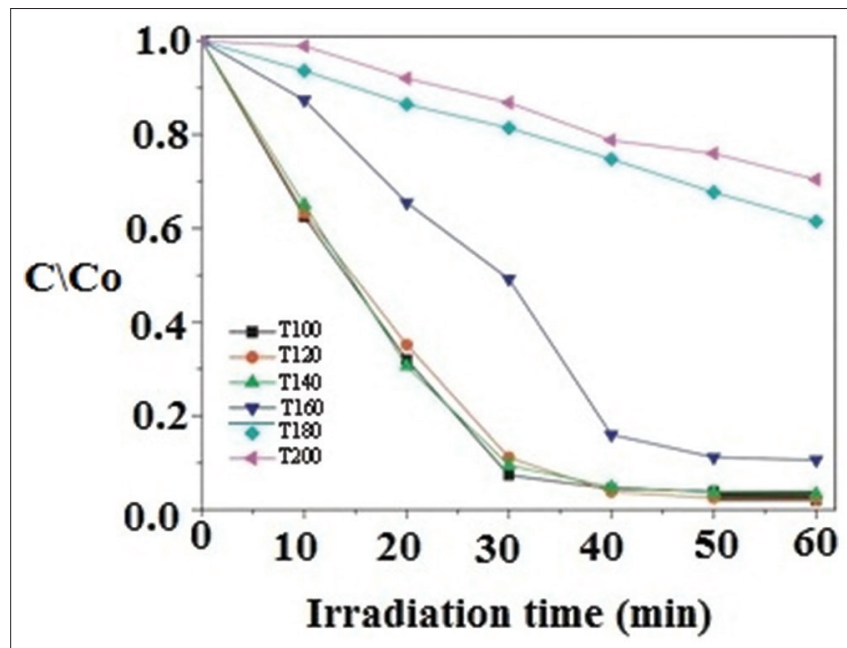

Fig. 6: Photocatalytic degradation efficiency of RhB over different catalysts prepared with various solvothermal temperature under visible light irradiation

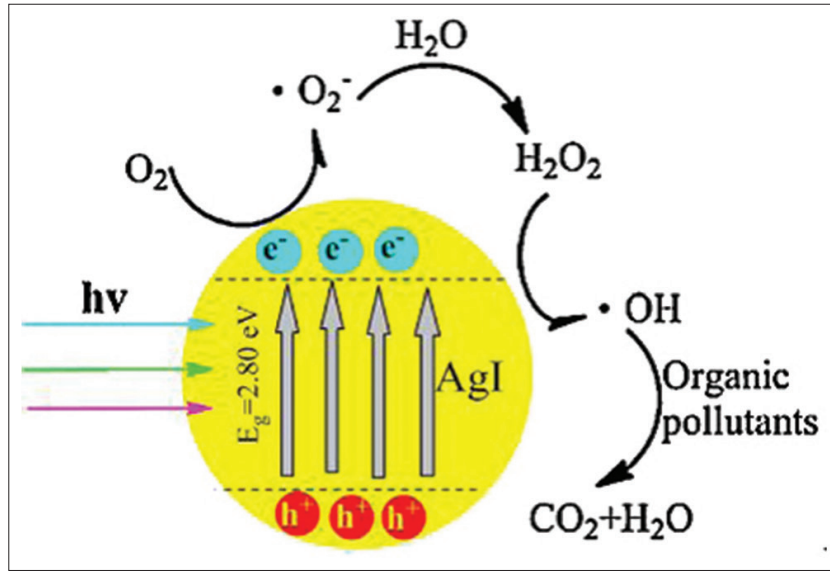

Fig. 7: The proposed reaction mechanism of the $\beta$-AgI system

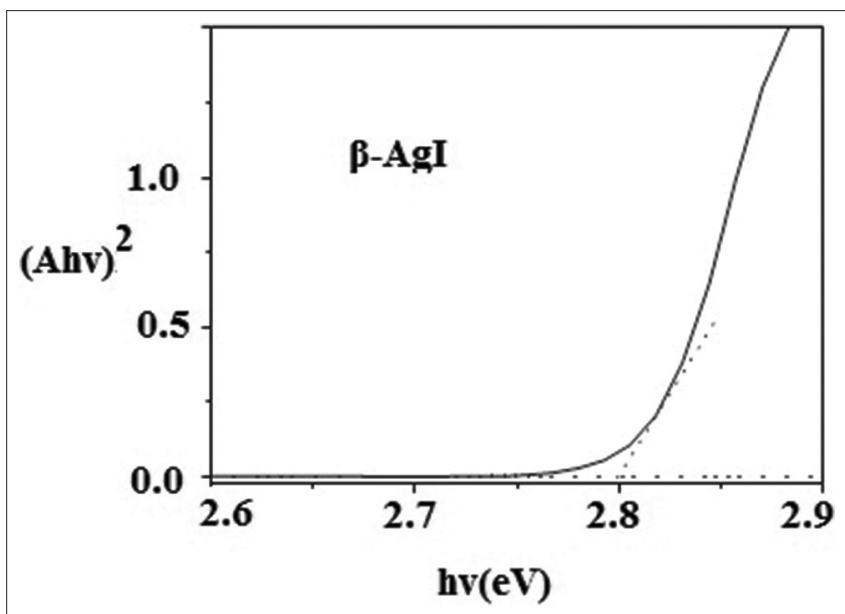

Fig. 8: The band gap of $\beta$-AgI sample
The antibacterial properties of silver iodide nanoparticles were evaluated using the cup diffusion method (Fig. 11). In this experiment, three wells were made on E. coli and $S$. aureus grown Petri plates. Different volumes of silver iodide nanoparticles of the same concentration were poured into these wells $(10 \mu \mathrm{L}, 25 \mu \mathrm{L}$, and $50 \mu \mathrm{L}$ ) and these plates were incubated for $24 \mathrm{~h}$. It was found that in all the four cases the zone of inhibition increased as the volume of the nanoparticle solution increased from $10 \mu \mathrm{L}, 25 \mu \mathrm{L}$, and $50 \mu \mathrm{L}$. In the case of Gram-positive bacteria ( $S$. aureus), when treated with silver iodide nanoparticles the diameter of the zone increased from $14 \mathrm{~mm}, 16 \mathrm{~mm}$ to $23 \mathrm{~mm}$ (Fig. 11a). In the case of Gram-negative bacteria (E. coli), the diameter of the zone obtained is $10 \mathrm{~mm}, 15 \mathrm{~mm}$, and $20 \mathrm{~mm}$ (Fig. 11b).

Green synthesis of AgI nanoparticles using the freshly prepared Ocimum sanctum leaf extract and their application as photocatalyst for the degradation of organic dyes such as methylene blue and methyl orange have been recently reported by the same author [38]. The PXRD

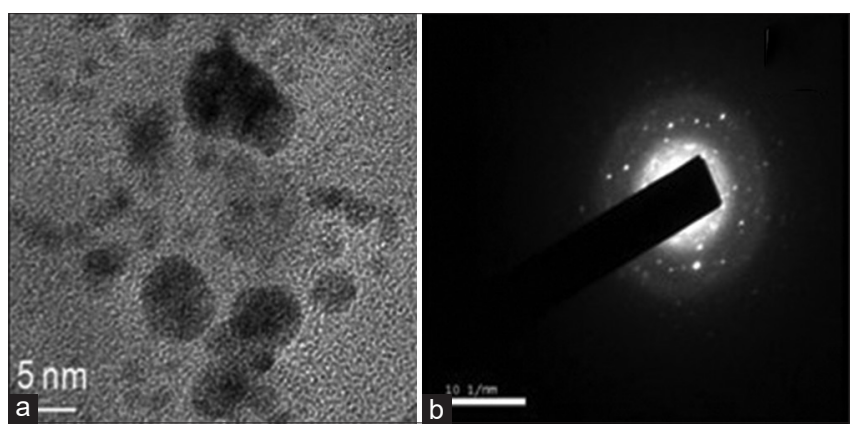

Fig. 9: (a) High resolution transmission electron microscopy image of the silver iodide nanoparticles and (b) shows selected area electron diffraction pattern of silver iodide nanoparticles

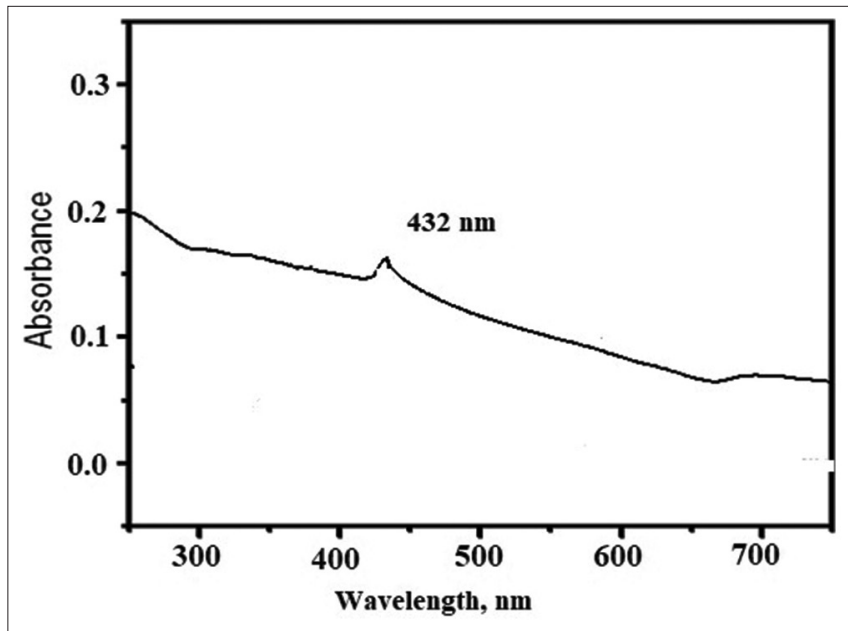

Fig. 10: Ultraviolet visible spectrum of silver iodide nanoparticles
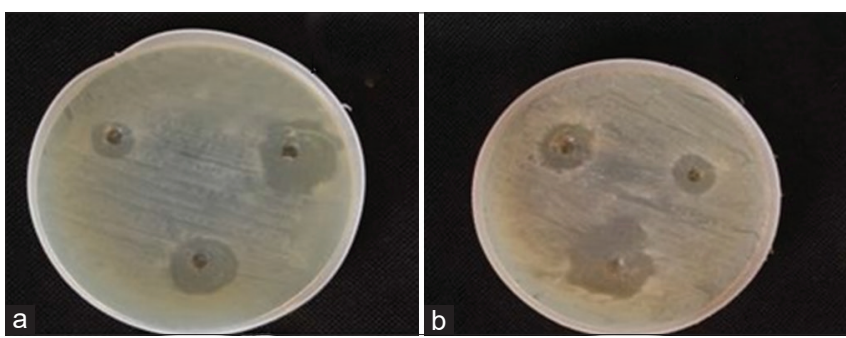

Fig. 11: Photograph images of the zone of inhibition of Staphylococcus aureus and Escherichia coli treated with (A \& B) silver iodide nanoparticles 
pattern of the silver iodide is represented in Fig. 12. The diffraction peaks at $2 \theta$ values $22.44^{\circ}, 23.81^{\circ}, 25.3^{\circ}, 39.32^{\circ}, 42.81^{\circ}$, and $46.40^{\circ}$ are assigned to (100), (002), (101), (110), (103), and (112) planes of $\beta$ - AgI, respectively.

Fig. 13a shows the SEM image of AgI NPs prepared through green synthesis by using the freshly prepared $O$. sanctum leaf extract. From the SEM image, spherical AgI NPs in the range of 125-375 nm was generated by green synthesis. Fig. 13b shows the elemental composition of the AgI NPs. The Ag/I atomic ratio in the AgI NPs obtained from the EDX analysis was approximately 1:1 The absence of other peaks which further indicates that the AgI has formed with high purity.

In the present review, FTIR analysis as shown in Fig. 14 of AgI NPs prepared by green synthesis of AgI nanoparticles using the freshly prepared $O$. sanctum leaf extract shows that the peaks peaked at 513.07 $\mathrm{cm}^{-1}$ are due to $\mathrm{C}-\mathrm{H}$ bending and the intense peaks peaked at 1217.08 $\mathrm{cm}^{-1}$ are due to the $\mathrm{C}-\mathrm{N}$ stretching vibrations. The absorption peaks are centered at $1367.53 \mathrm{~cm}^{-1}$ which represents the $\mathrm{C}-\mathrm{H}$ rocking and the characteristic peak at $1737.86 \mathrm{~cm}^{-1}$ corresponds to the $\mathrm{C}=0$ stretching mode of vibration. In the spectra, the peak indexed at $2123.62 \mathrm{~cm}^{-1}$ represents the characteristic bands of $\mathrm{N}-\mathrm{H} / \mathrm{C}-\mathrm{O}$ stretching vibration. The common broad absorption bands for the sample are centered at $3439.07 \mathrm{~cm}^{-1}$ attributed to the $\mathrm{O}-\mathrm{H} / \mathrm{N}-\mathrm{H}$ bending of phenolic and amide groups. The presence of all the above peaks indicates that $O$. sanctum leaf extract acts as capping agent on the surface of metal halide NPs.

Fig. 15 (a) shows the photocatalytic activity of AgI NPs for the MB solution irradiated under the visible light for $60 \mathrm{~min}$ and also it can be observed that the initial bluish color sample gradually becomes completely colorless. Fig. 15 (b) shows the decrease in the absorbance peak of MB at $664 \mathrm{~nm}$. Fig. 15 (c) shows the photocatalytic degradation

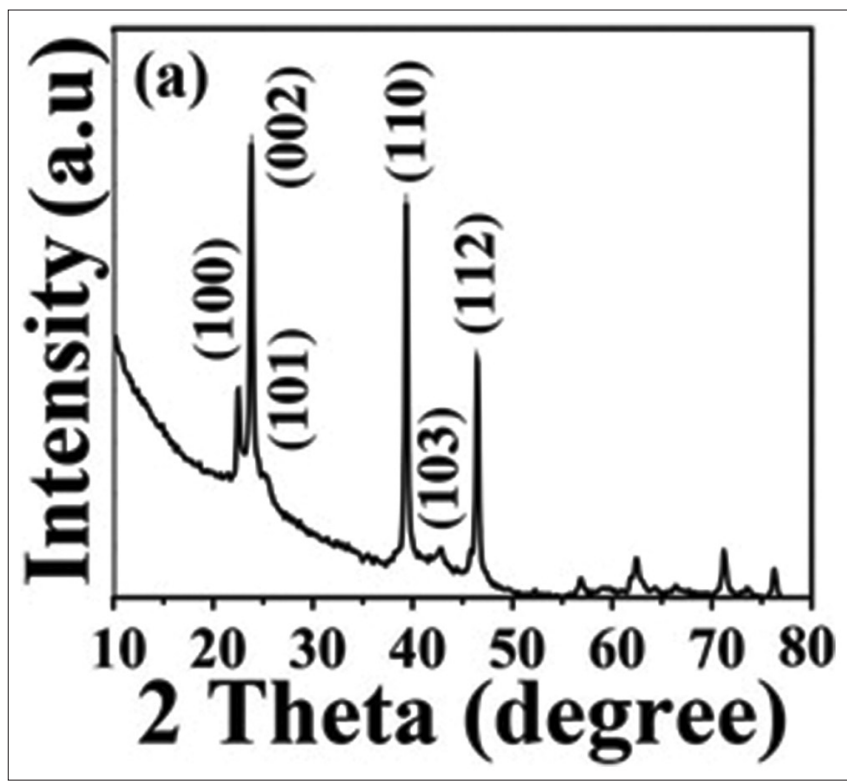

Fig. 12: The P X-ray Diffraction pattern of AgI nanoparticles

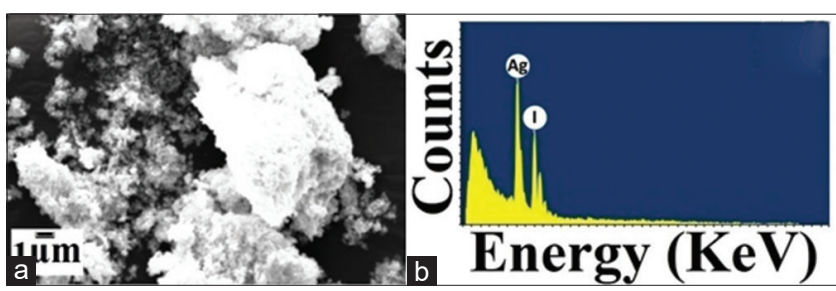

Fig. 13: (a) Scanning electron microscopy image of AgI NPs and (b) EDX analysis with respect to the function of time and concentration of the MB dye. From Fig. 15 (c), it is observed that when the time is increased the concentration of the dye is reduced and the percentage of degradation of dye increases with respect to the time as presented Fig. 16 (c) inset. The results obtained in the present investigation are very similar to the Rodriguez-Cabo et al reported work for the degradation of MB dye using $\mathrm{AgCl}$ nanocatalyst [39]. According to the current study, the degradation of highly concentrated $20 \mathrm{ppm}$ MB dye with AgI sample degrades the $99.5 \%$ organic dye in 60 min of time. It is well observed that the AgI NPs synthesized in the current research work has shown better performance compared to AgCl NPs reported by RodriguezCabo et al.

Similarly explanation is reported for the photocatalytic activity of AgI NPs for the MO solution as shown in Fig. 16 (a-b).

\section{APPLICATIONS OF SILVER IODIDE NANOPARTICLES}

According to reports, millions of people around the world are in danger of illness or even death because their drinking water is infected by the harmful bacteria. Therefore, eliminating harmful bacteria in water simultaneously is of great importance. AgI nanoparticles doped with CNT have been employed as antibacterial agent and used to treat the water containing bacteria. In addition, CNT/AgI nanoparticles also used for photocatalytic degradation of $\mathrm{RhB}$ under visible light irradiation and finally used to treat the affluent containing dyes. The results suggest that the CNT/AgI can degrade the pollutant and kill the bacterium at the same time and the CNT/AgI can be used as a double function material [29].

Li et al. have reported the hexagon-shaped $\beta$-AgI nanoplates fabrication through a simple solvothermal route using ionic liquids and demonstrated their potential as photocatalyst for the degradation of $\mathrm{RhB}$ dye under the visible light irradiation. The photocatalysts samples heated at $100^{\circ} \mathrm{C}, 120^{\circ} \mathrm{C}, 140^{\circ} \mathrm{C}, 160^{\circ} \mathrm{C}, 180^{\circ} \mathrm{C}$, and $200^{\circ} \mathrm{C}$ for $24 \mathrm{~h}$ were, respectively, named T100, T120, T140, T160, $\mathrm{T} 180$, and T200. The photocatalytic activity was in the following order: $\mathrm{T} 100 \approx \mathrm{T} 120 \approx \mathrm{T} 140>\mathrm{T} 160>\mathrm{T} 180>\mathrm{T} 200$ [34].

Kaliammal et al. have reported the synthesis of AgI nanoparticles from polymer (PEG-PPG-PEG) protected silver nanoparticles for $30 \mathrm{~min}$ by reaction with aqueous solution of iodine solution. HRTEM image of silver iodide nanoparticles show particles of size in the range of $20 \mathrm{~nm}-$ $35 \mathrm{~nm}$. The antibacterial activities of the as-fabricated AgI were also

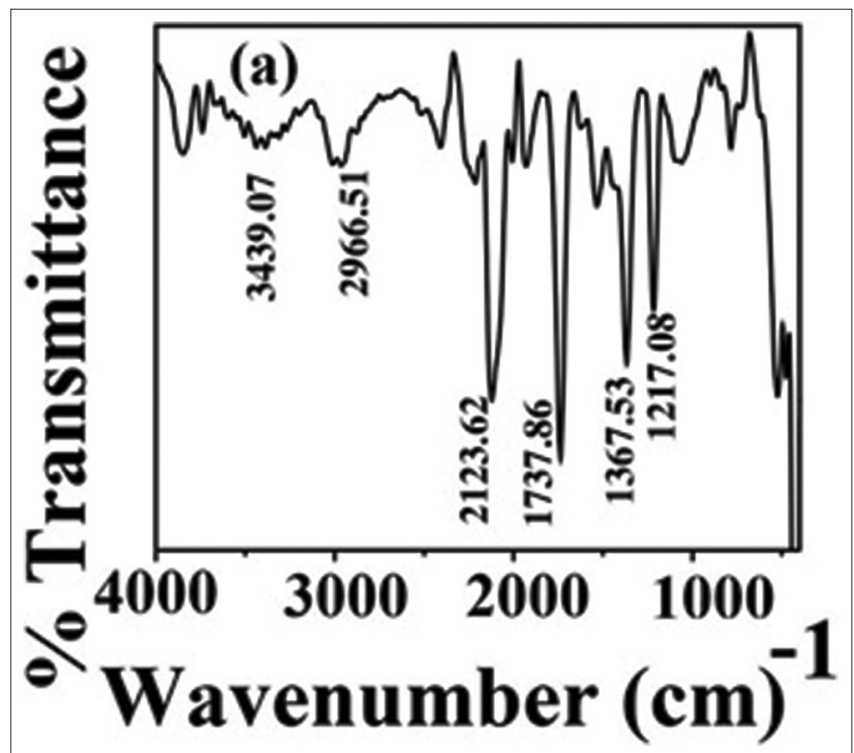

Fig. 14: Characterization of silver iodide nanoparticles using Fourier transform infrared studies 


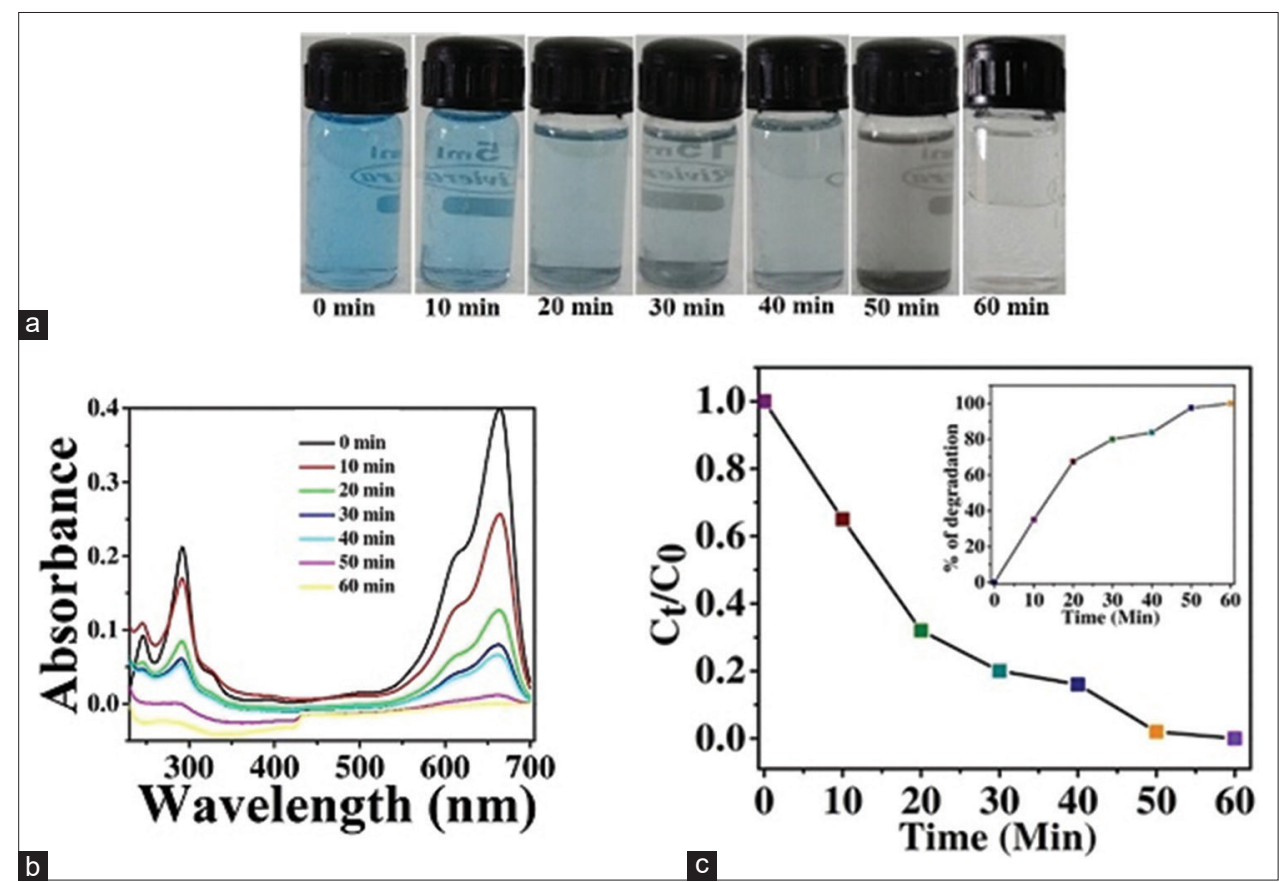

Fig. 15: (a) Decoloration of the samples (b) photocatalytic degradation of MB @ Evolution in time of the system [MB+ AgI+ Visible light]

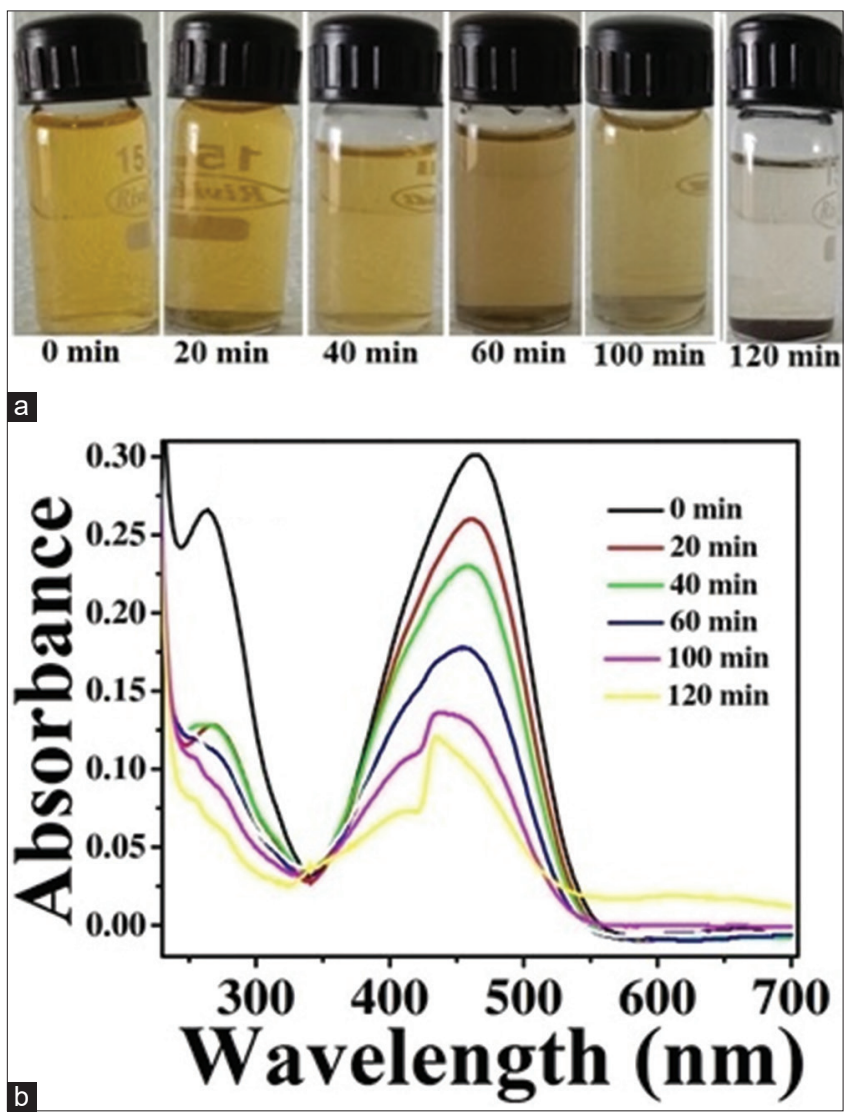

Fig. 16: (a) Decoloration of the samples (b) photocatalytic degradation of MO

studied through the inactivation of Gram-positive and Gram-negative bacteria [36].

The Apsana et al. have used the 0 . sanctum leaf extract for the biosynthesis of AgI nanoparticles and demonstrated their antibacterial and catalyst potential. In many studies, silver iodide nanoparticles were used as photocatalyst for the degradation of organic dyes. Silver iodide nanoparticles prepared by biological approach have been tested for its photocatalytic activity for the degradation of organic dyes such as methylene blue and methylene orange. This green fabrication of catalyst is far better to other methods. Green synthesis involves no toxic chemicals and pollution free environment. The presence of polyphenols indicated that they act as reducing and capping agents for the AgI nanoparticles. Green synthesis of AgI nanoparticles can be used as a potential catalyst of future [38].

\section{CONCLUSION}

Silver iodide nanoparticles are widely used in biomedical materials because of their antibacterial property. Their applications also extend to optical and photocatalytic materials. Silver iodide nanoparticles can be synthesized by chemical and physical methods with the presence of reducing agents, or SDR method, respectively. In addition, CNT/AgI nano hybrids are fabricated by using solvothermal method. CNT/AgI hybrid is widely investigated for its excellent photocatalytic activity for degrading RhB. In addition, CNT addition to AgI nanoparticles will be collectively enhance the antibacterial property by killing the $E$. coli.

In this work, the methods employed to prepare the AgI nanoparticles and hybrid material CNT/AgI and their applications are presented and reviewed.

\section{ACKNOWLEDGMENTS}

Dr. P. P. George thanks the Management, Mangalam College of Engineering, Ettumanoor, Kerala, India, for encouraging to complete this research work.

\section{CONFLICT OF INTEREST}

The author declares there is no conflict of interest.

\section{REFERENCES}

1. Wang P, Huang BB, Lou Z, Zhang X, Qin X, Zheng Z, et al. Synthesis of highly efficient $\mathrm{Ag} @ \mathrm{AgCl}$ plasmonic photocatalysts with various structures. Chem Eur J 2010;16:538-44.

2. Wang P, Huang BB, Zhang XY, Qin XY, Jin HY, Dai YZ, et al. Highly 
efficient visible-light plasmonic photocatalyst Ag@AgBr. Chem Eur J 2009;15:1821-4.

3. Wang P, Huang BB, Qin XY, Zhang YX, Dai Y, Wei JY, et al. Ag@ $\mathrm{AgCl}$ : A highly efficient and stable photocatalyst active under visible light. Angew Chem Int Ed 2008;47:7931-33.

4. Lou ZZ, Wang ZY, Huang BB, Dai Y. Synthesis and activity of plasmonic photocatalysts. ChemCatChem 2014;9:2456-76.

5. Jiang W, An CH, Liu JX, Wang ST, Zhao LM, Guo WY, et al. Facile aqueous synthesis of $\beta$-AgI nanoplates as efficient visible-lightresponsive photocatalyst. Dalton Trans 2014;43:300-5.

6. Yuvasravan R, Apsana G, George PP, Genish I, Ben-David MS, Koltypin Y, et al. Synthesis of WS2 and WSe2 nanowires on stainless steel coupon by reaction under autogenic pressure at elevated temperature method. Appl Nanosci 2015;6:855-62.

7. George PP, Pol VG, Koltypin Y, Ben-David MS, Genish I, Gedanken A. Chemical reactions under autogenic pressure at elevated temperature to fabricate photo-luminescent $\mathrm{Ga} 2 \mathrm{O} 3$ nanocrystals and its coatings. RSC Adv 2011;1:619-24

8. Apsana G, George PP, Devanna N. Facile green synthesis and characterization of calcium pyrophosphate nanoparticles using D-Glucose. Mater Today Proc 2017;4:10913-20.

9. Apsana G, George PP. Enhanced antibacterial, and photocatalytic properties of Bio-mimetically synthesized $\mathrm{AgCl}$ nanostructures using various proportions of Ocimum leaf extract. Mater Focus 2018;7:628-39.

10. Hu W, Chen S, Li X, Shi S, Shen W, Zhang X, et al. In situ synthesis of silver chloride nanoparticles into bacterial cellulose membranes. Mater Sci Eng C 2009;29:1216-9.

11. Tan H, Fan WY. Laser-based synthesis of core Ag-shell AgI nanoparticles. Chem Phys Lett 2005;406:289-93

12. Tiwari JP, Rao RK. Template synthesized high conducting silver chloride nanoplates. Solid State Ionics 2008;179:299-304.

13. Bai J, Li Y, Li M, Wang S, Zhang C, Yang Q. Electrospinning method for the preparation of silver chloride nanoparticles in PVP nanofiber. Appl Surface Sci 2008;254:4520-3

14. Validzic IL, Jokanovic V, Uskokovic DP, Nedeljkovic JM. Influence of solvent on the structural and morphological properties of AgI particles prepared using ultrasonic spray pyrolysis. Mater Chem Phys 2008; 107:28-32.

15. Abbasi AR, Morsali A. Syntheses and characterization of AgI nanostructures by ultrasonic method: Different morphologies under different conditions. Ultrason Sonochem 2010;17:572-8.

16. Yuvasravana R, George PP. A green protocol for synthesis of MA12O4, $[\mathrm{M}=\mathrm{Cu}$ and $\mathrm{Co}]$ spinels under microwave irradiation method. Int $\mathrm{J}$ Nanosci 2016;15:1650033-10.

17. Yuvasravana R, George PP, Devanna N. Synthesis and characterization of spinel metal aluminate by a simple microwave assisted green synthesis. Mater Today Proc 2017;4:10664-71.

18. Yuvasravana R, George PP, Devanna N. Biosynthesis of MO-MCo2O4 $[\mathrm{M}=\mathrm{Zn}$ and $\mathrm{Cu}]$ Composites from peel extract of pomegranate fruits"Punica granatum". Int J Innov Res Sci Eng Technol 2017;6:4.

19. Apsana G, George PP, Devanna N, Yuvasravana R. Enhanced morphology and efficient one-pot microwave green synthesis of Ag3PO4 nanocubes and their optical and photocatalytic properties. J Bionanosci 2017;11:428-34.

20. Devendiran RM, Kumar CS, Kumar MR, Giriprasath R, Sivakumar S, Sobhana S, et al. Sunlight mediated biosynthesis and characterisation of gold nanoparticles using Pisonia grandis leaf extract for biomedical applications. J Biomater Tissue Eng 2014;4:430-8.

21. Xu H, Yan J, Xu YG, Song YH, Li HM, Xia JX, et al. Novel visiblelight-driven $\mathrm{AgX} /$ graphite-like $\mathrm{C} 3 \mathrm{~N} 4(\mathrm{X}=\mathrm{Br}$, I) hybrid materials with synergistic photocatalytic activity. Appl Catal B 2013;129:182-93

22. Li YZ, Zhang H, Guo ZM, Han JJ, Zhao XJ, Zhao QN, et al. Highly efficient visible-light-induced photocatalytic activity of nanostructured $\mathrm{AgI} / \mathrm{TiO}$ photocatalyst. Langmuir 2008;24:8351-7.

23. $\mathrm{Hu} \mathrm{C}, \mathrm{Hu} \mathrm{XX}$, Wang LS, Qu JH, Wang AM. Visible-light-induced photocatalytic degradation of azodyes in aqueous $\mathrm{AgI} / \mathrm{TiO}$ dispersion. Environ Sci Technol 2006;40:7903-7.

24. Wu D, Long M. Enhancing visible-light activity of the self-cleaning $\mathrm{TiO}_{2}$-coated cotton fabrics by loading AgI particles. Surf Coat Technol 2011;206:1175-9.

25. Bi YP, Ouyang SX, Cao JY, Ye JH. Facile synthesis of rhombic dodecahedral AgX/Ag3PO4 $(\mathrm{X}=\mathrm{Cl}, \mathrm{Br}, \mathrm{I})$ heterocrystals with enhanced photocatalytic properties and stabilities. Phys Chem Chem Phys 2011;13:10071-5.

26. Cheng H, Huang B, Dai Y, Qin X, Zhang X. One-step synthesis of the nanostructured $\mathrm{AgI} / \mathrm{BiOI}$ composites with highly enhanced visible-light photocatalytic performances. Langmuir 2010;26:6618-24

27. Xu H, Yan J, Xu Y, Song Y, Li H, Xia J, et al. Novel visible-light-driven $\mathrm{AgX}$ /graphite-like C3N4 (X= Br, I) hybrid materials with synergistic photocatalytic activity. Appl Catal B 2013;129:182-93.

28. Eliseev AA, Yashina LV, Brzhezinskaya MM, Chernysheva MV, Kharlamova MV, Verbitsky NI, et al. Structure and electronic properties of $\mathrm{AgX}(\mathrm{X}=\mathrm{Cl}, \mathrm{Br}, \mathrm{I})$-intercalated single-walled carbon nanotubes. Carbon 2010;48:2708-21.

29. Yuanguo X, Shuquan H, Haiyan J, Liquan J, Minqiang H, Hui X, et al. Facile synthesis of CNT/AgI with enhanced photocatalytic degradation and antibacterial ability. RSc advances. RSC Adv 2016;6:6892-905.

30. Hawari NL, Johan MR. Synthesis and characterizations of AgI nanoparticles via mechanochemical reaction. J Alloys Compounds 2011;509:2001-6.

31. Ghomi JS, Ghasemzadeh MA. Silver iodide nanoparticle as an efficient and reusable catalyst for the one-pot synthesis of benzofurans under aqueous conditions. J Chem Sci 2013;125:1003-8.

32. Li CC, Wang YH, Tai CY. The $1^{\text {st }}$ International Seminar on Fundamental and Application. November 3-4; 2010.

33. Yamasaki S, Yamada T, Kobayashi H, Kitagawa H. Preparation of Sub-10 nm AgI nanoparticles and a study on their phase transition temperature. Chem Asian J 2013;8:73-5.

34. Fenga S, Xub H, Liub L, Song Y, Li H, Xub Y, et al. Controllable synthesis of hexagon-shaped $\beta$-AgI nanoplates in reactable ionic liquid and their photocatalytic activity. Colloids Surfaces A Physicochem Eng Aspects 2012;410:23-30.

35. Bi Y, Ouyang S, Cao J, Ye J. Facile synthesis of rhombic dodecahedral $\mathrm{AgX} / \mathrm{Ag} 3 \mathrm{PO} 4(\mathrm{X}=\mathrm{Cl}, \mathrm{Br}, \mathrm{I})$ heterocrystals with enhanced photocatalytic properties and stabilities. Phys Chem Chem Phys 2011;13:10071-5.

36. Kaliammal P, Rosemary MJ, Khadar MA. Synthesis, characterization and applications of polymer protected silver and silver iodide nanoparticle. Indian J Nanotechnol Appl 2013;1:49-60.

37. Chen S, Ida T, Kimura KJ. Thiol-derivatized AgI nanoparticles: Synthesis, characterization, and optical properties. Phys Chem B 1998;102:6169-76.

38. Apsana G, George PP, Devanna N, Yuvasravana R. One-Step green synthesis, characterization, optical, and photocatalytic properties of metal iodide ( $\mathrm{MI}, \mathrm{M}=\mathrm{Ag}$ and $\mathrm{Cu}$ ) nanoparticles. J Bionanosci 2018;12:191-9.

39. Rodriguez-Cabo B, Rodriguez-Palmeiro I, Corchero R, Rodil R, Rodil E, Arce A, et al. Photocatalytic degradation of methyl orange, methylene blue and rhodamine $\mathrm{B}$ with $\mathrm{AgCl}$ nanocatalyst synthesised from its bulk material in the ionic liquid [P6 66 6 14]C. Water Sci Technol 2016;75:128-40 